\title{
DURÔMETRO PORTÁTIL PARA MADEIRAS
}

\author{
Adriano Wagner Ballarin ${ }^{1}$, Roberto Antonio Colenci ${ }^{2}$ e Hernando Alfonso Lara Palma ${ }^{3}$
}

\section{RESUMO}

A dureza para madeiras é normalmente avaliada pelo método Janka, no qual uma esfera de seção diametral de $1 \mathrm{~cm}^{2}$ é forçada contra a superfície da madeira, até a penetração equivalente a um raio. A dureza é convencionalmente definida pela tensão na superfície da madeira que promoveu essa penetração. Esse método apresenta alguns inconvenientes para avaliação nas condições de campo, sobretudo pela magnitude dos esforços envolvidos (de 7 a $12 \mathrm{kN}$ ) e pela dificuldade de controle da profundidade de penetração da esfera.

Neste trabalho relata-se o desenvolvimento de um durômetro portátil para madeiras embasado, no geral, na metodologia Brinell, com mensuração dos diâmetros da calota endentada no material sob análise, após sofrer impacto de uma massa em queda livre. O trabalho reporta os ensaios de calibração inicial do equipamento, que foram conduzidos utilizando-se 16 lotes de madeiras de reflorestamentos e nativas, variando-se, além das espécies, as procedências. Os ensaios foram conduzidos com as madeiras na umidade de recebimento e consistiram de testes laboratoriais de dureza Janka (seguindo-se metodologias de normas técnicas da ABNT) e testes com uso do equipamento desenvolvido.

A análise dos resultados foi encaminhada com o estabelecimento de correlações de regressão entre a dureza avaliada pelo equipamento e a dureza Janka. Para a energia de endentação de 200 kgf.mm, o equipamento revelou boa correlação com os resultados de dureza Janka, o que o abonam como instrumento para avaliação em campo da dureza de madeiras.

Palavras-chave: Equipamento portátil, Dureza Brinell, Dureza Janka, Calibração

1- Associate Professor - Universidade Estadual Paulista - UNESP - Dep. Engenharia Rural / Fazenda Lageado, P.O. Box 237 / 18603-970 - Botucatu-SP-Brazil E--mail: awballarin@fca.unesp.br

2- Professor - Faculdade de Tecnologia de Botucatu-S.P-Brazil E-mail: colenci@uol.com.br

3 -Assistant Professor - Universidade Estadual Paulista - UNESP - Dep. Recursos Naturais / Fazenda Lageado, P.O. Box 237 / 18603-970 - Botucatu-SP-Brazil E-mail: larapalma@fca.unesp.br 


\section{PORTABLE DYNAMIC WOOD HARDNESS TESTER}

\section{SUMMARY}

Hardness is evaluated for wood using Janka Hardness method, in which a metal sphere (diametrical area equal to $1 \mathrm{~cm}^{2}$ ) is forced against wooden specimen reaching a penetration equivalent to one radius. Hardness strength is conventionally defined by the stress on specimen surface that promoted this penetration. This method presents several inconvenience to in-field evaluation, related to the magnitude of involved loads (from 7 to $12 \mathrm{kN}$ ) and to the control of depth penetration.

This paper presents the development of a portable hardness tester for wood, based on Brinell hardness method, measuring diameters of indented spherical calotte, after an impact (falling mass). This paper still reports calibration tests using 16 parcel of forest and native wood, varying its species and procedance. Tests were performed with timber on its moisture above the FSP (fiber saturation point) and consisted of reference laboratory tests (mainly Janka hardness following ABNT Brazilian codes) and tests using the developed hardness tester.

The result analysis was carried out with the regression correlations between the hardness evaluated by the equipment and other properties of interest for timber. The results revealed the great functionality, usefulness and low cost of the equipment, when compared to the commercially available alternatives. For energy indentation of $200 \mathrm{kgf} . \mathrm{mm}$, good linear correlation with Janka hardness, that approves it as portable tester for in-field evaluation of wood hardness .

Keywords: Portable tool, Brinell hardness, Janka hardness, Calibration 


\section{INTRODUÇÃO}

A grande maioria das Companhias de Estradas de Ferro brasileiras utiliza em larga escala dormentes de madeira e a malha ferroviária brasileira, com cerca de 30.000 quilômetros de extensão emprega dormentes de madeira em mais de $80 \%$ de sua via permanente.

$\mathrm{Na}$ fase de implantação dessas ferrovias havia grande disponibilidade de madeiras nativas de uso consagrado para esse fim. Com a drástica alteração dessa realidade, essas madeiras atingiram preços proibitivos, exigindo novas alternativas. Assim, os programas de reposição de dormentes nas vias permanentes têm envolvido altas cifras, o que exige soluções imediatas para redução de custo. Conta-se com o fato adicional de que a maioria das empresas ferroviárias brasileiras enfrenta uma situação muito difícil, com déficits acumulados que se agigantam ano a ano. A alternativa, a curto e médio prazos, tem sido a viabilização do uso de madeiras de reflorestamento para a confecção de dormentes, aos moldes da sistemática já adotada em outros países.

O código normativo que especificava e balizava essa aplicação da madeira - NBR 7511 - Dormentes de madeira (ABNT, 1982) - encontra-se desatualizado e incompleto para dar suporte técnico a essa nova realidade. Na maioria dos processos para especificação de dormentes, os aspectos técnicos envolvidos têm sido ditados por documentos internos das próprias empresas ferroviárias, mais abrangentes, completos e atuais, em substituição a NBR 7511. A necessidade da completa revisão e ampliação do atual código normativo já foi evidenciada em trabalho de Ballarin (1996).

A Faculdade de Ciências Agronômicas da UNESP de Botucatu, São Paulo-Brasil, através do CEVEMAD - Centro Virtual de Pesquisas em Madeiras, vem trabalhando desde 1992 com a análise teórica e experimental de dormentes prismáticos de madeira de reflorestamento. A busca atual é por uma técnica, aplicável em condições de campo, que possa auxiliar na decisão pela aceitação ou rejeição de dormentes de um lote amostrado, considerando-se seu potencial de desempenho mecânico como parâmetro balizador da decisão.

Neste trabalho, parte do estudo mais amplo descrito, relata-se o desenvolvimento e calibração de um equipamento para avaliação em campo da dureza de madeiras utilizadas na produção de dormentes ferroviários.

\section{ANTECEDENTES E JUSTIFICATIVA}

As ferrovias brasileiras vêm enfrentando várias dificuldades no tocante à substituição dos dormentes em suas vias permanentes, uma vez que a necessidade de manutenção é cada vez mais imediata, por conta do atual estado de deterioração em que se encontram.

$\mathrm{Na}$ escolha da espécie mais apropriada para esse fim têm-se usado critérios baseados, muitas vezes, apenas na experiência das empresas ferroviárias, ocasionando aquisições indevidas. Adicionalmente, a pressão legal pela restrição na extração de madeiras provenientes de diversas espécies nativas tem feito com que as empresas busquem, em proporções crescentes, madeiras de reflorestamento para confecção dos novos dormentes. 
Ballarin (1996) citou, a exemplo de outros autores (como Niederauer, 1982; Tuset \& Taibo, 1987; Sales \& Lahr, 1991; Nogueira \& Lahr, 1992; Ballarin, Franco \& Yojo, 1998; Ballarin, 1999) que a madeira do gênero eucalipto é, dentre as provenientes do reflorestamento, a mais indicada para uso na produção de dormentes para ferrovias. De fato, neste sentido, várias são as constatações científicas e práticas, estas últimas levadas a cabo notadamente por empresas ferroviárias.

Assim, utilizada com diferentes formatos, a madeira de eucalipto pode ser vista, em muitos casos, como uma "tábua de salvação" na luta contra o grave problema ferroviário de abastecimento de dormentes para as vias permanentes.

Por outro lado, a grande semelhança anatômica entre algumas espécies do gênero Eucalyptus dificulta o processo de aceitação ou rejeição dos dormentes já serrados. Nota-se, portanto, a necessidade urgente de definição de ensaios rápidos, eficientes e aplicáveis nas condições de campo, para auxiliar no processo de aceitação e rejeição desses elementos.

Os ensaios de dureza paralela e normal às fibras têm sido utilizados como ferramenta para classificação inicial de peças de madeira, sobretudo pela sua praticidade (Colenci, Ballarin \& Rocha, 2002). Embora de efeito localizado, na medida em que seus resultados são atribuíveis somente a uma pequena região da peça - nas circunvizinhanças do ponto de endentação da esfera - seus resultados apresentam boa correlação com a resistência à compressão paralela às fibras da madeira, parâmetro utilizado na atribuição de classes de resistência ao material.

Colenci (2002), trabalhando com madeiras das famílias Lauraceae, Vochysiaceae e da espécie Eucalyptus citriodora, estudou a correlação entre a dureza e a resistência à compressão paralela às fibras da madeira. Do estudo, obteve correlações com coeficientes de determinação de 0,80 e 0,82. A Figura $N^{\circ} 1$ apresenta as correlações entre a dureza paralela e a resistência compressão paralela às fibras. O teor de umidade dos corpos-de-prova, no momento dos ensaios, variou de $15 \%$ a $25 \%$.

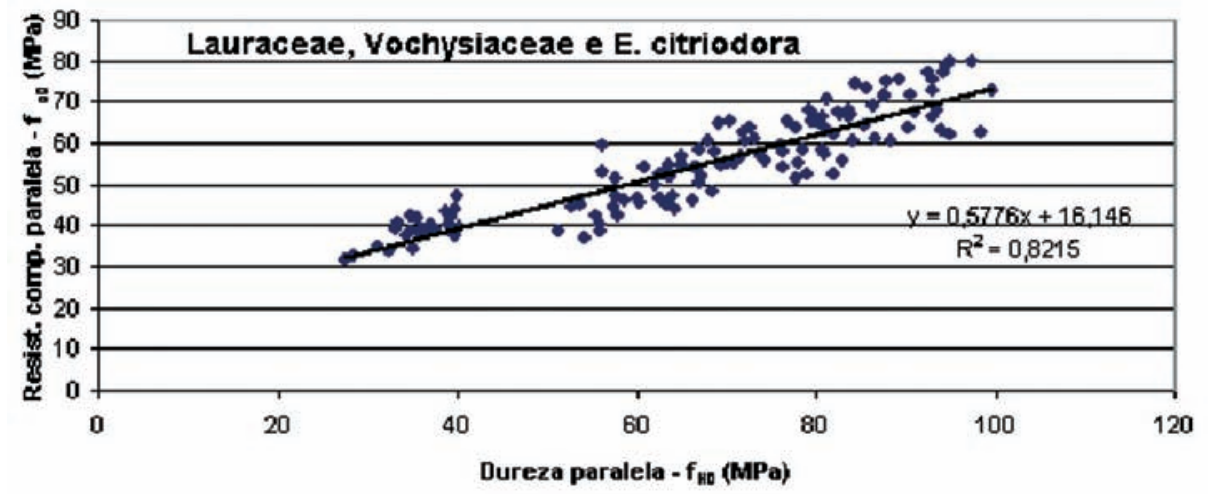

Figura $N^{\circ} 1$

CORRELAÇÃO ENTRE A DUREZA PARALELA ÀS FIBRAS E A RESISTÊNCIA À COMPRESSÃO PARALELA ÀS FIBRAS - VALORES PARA UMIDADES VARIÁVEIS NOS LOTES 
Dentre os métodos empregados para a avaliação da dureza nos diferentes materiais, o método Janka é, sem dúvidas, o mais adequado à madeira. Em trabalho recente, Bektas et al.(2001) estudaram a utilização da dureza Brinell - indicada em princípio para o aço e de uso pouco tradicional na tecnologia da madeira - como ferramenta para avaliação da qualidade desse material. A existência de correlações estatisticamente significativas entre a dureza Brinell e a dureza Janka, confirmadas por Colenci (2006) abonaria a prática de utilização dessa dureza para ensaios em madeiras.

Essa opção se justificaria, ainda, pela menor magnitude das forças envolvidas no ensaio Brinell (em relação ao ensaio de dureza Janka) e pela dificuldade de se controlar, em condições de campo, a profundidade de penetração da esfera, exigida no ensaio de dureza Janka.

Considerando-se os altos preços dos equipamentos portáteis de dureza Brinell, evidencia-se a importância e oportunidade do desenvolvimento de um equipamento para a avaliação em campo da dureza de madeiras, com base no método Brinell, com baixo custo e facilidade de utilização.

\section{MATERIAL E MÉTODOS}

A escolha inicialmente feita foi a de desenvolvimento de um equipamento semelhante ao utilizado para avaliação da dureza Brinell (com carga de endentação fixa e avaliação posterior da superfície endentada) tendo-se em conta que a dureza Brinell mobiliza forças de menor magnitude (em comparação com aquelas requeridas na metodologia Janka para madeiras) e a dificuldade de se controlar, em condições de campo, a profundidade de penetração da esfera exigida no ensaio de dureza Janka.

Considerando-se os mecanismos - passíveis de utilização em condições de campo para mobilizar a força necessária à endentação superficial de esfera de aço no material em estudo, optou-se por utilizar o mecanismo de endentação por queda livre de massa (com energias de endentação variáveis), em detrimento da cravação com uso de atuador hidráulico e endentação por mobilização de força de uma mola comprimida. A escolha recaiu na opção que resultava em equipamento mais leve (sem necessidade de pesados reservatórios para óleo dos sistemas hidráulicos), mobilizando força constante ao longo do tempo, o que não ocorre, na maioria das vezes, com sistemas que utilizam mola.

Considerando-se os resultados de Dal Pogetto (2005), no tocante à igualdade estatística das durezas Janka paralela ( $\mathrm{fH} 0$ ) e normal às fibras ( $\mathrm{fH} 90$ ), e considerando-se a maior facilidade de mensuração da dureza normal às fibras em condições de campo, optou-se por mensurar somente essa variável.

Os ensaios de dureza com o durômetro portátil foram realizados em quatro situações distintas apresentando variação da energia de endentação ou da massa em queda livre, tendo os seguintes parâmetros:

Situação 1 - Queda livre de uma massa de $1 \mathrm{~kg}$, à altura de $100 \mathrm{~mm}$ (Energia 100 kgf.mm) 
Situação 2 - Queda livre de uma massa de $1 \mathrm{~kg}$, à altura de $200 \mathrm{~mm}$ (Energia 200 kgf.mm)

Situação 3 - Queda livre de uma massa de $2 \mathrm{~kg}$, à altura de $100 \mathrm{~mm}$ (Energia 200 kgf.mm)

Situação 4 - Queda livre de uma massa de 2kg, à altura de 200mm (Energia 400 kgf.mm)

O valor da dureza assim avaliada foi estimado com base na equação:

$$
\mathrm{E}=\frac{2 \text { Energia }}{\mathrm{p} D\left(D-\sqrt{D^{2}-d^{2}}\right)} \quad \text { onde: }
$$

Energia: Energia disponibilizada na queda livre da massa (em kgf.mm)

D: $\quad$ Diâmetro do indentador metálico (fixado em 10mm)

D: $\quad$ Ddiâmetro da calota endentada na madeira (em $\mathrm{mm})$

As Figuras $\mathrm{N}^{\circ} 2$ e $\mathrm{N}^{\circ} 3$ ilustram detalhes do equipamento, seus acessórios e forma de operação.


a) Aspectos gerais do equipamento

b) Forma de utilização na madeira para avaliação da sua dureza. 
Figura $\mathrm{N}^{\circ} 2$

\section{DURÔMETRO PORTÁTIL PARA MADEIRAS}
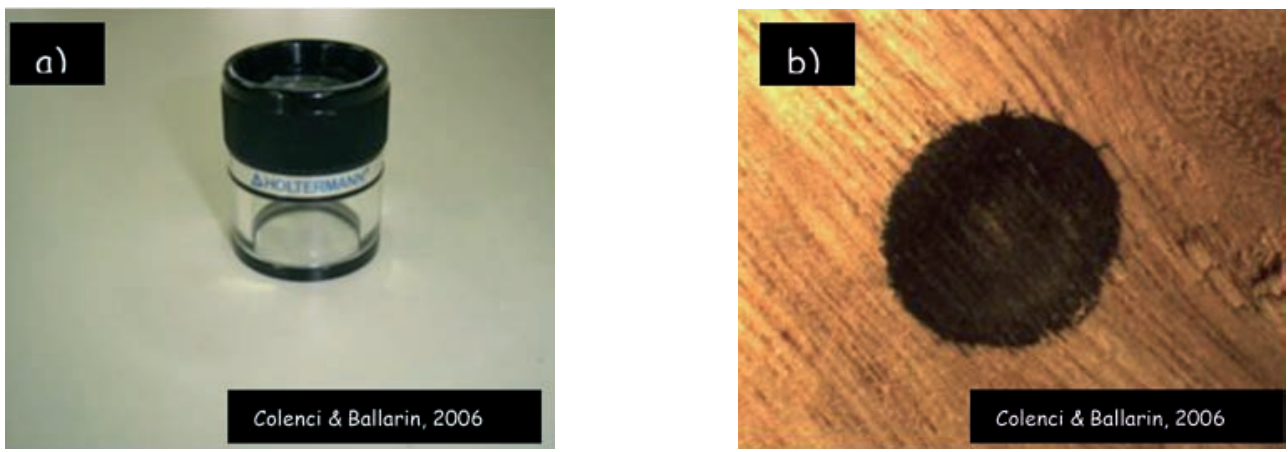

a)Lupa graduada marca Holtermann modelo LH 20/10X b) Calota esférica obtida.

Figura $\mathrm{N}^{\circ} 3$

ENDENTAÇÃO NO ENSAIO DE DUREZA BRINELL

Para a calibração do equipamento buscou-se a utilização de madeiras de diferentes procedências, reunidas em lotes, cada um deles potencializando algumas características (idade do plantio, espécie botânica, tipo de lenho, entre outras) de interesse ao estudo. A Tabela 1 apresenta os dados principais dos lotes de madeiras amostrados.

Cada lote foi formado por 12 vigas prismáticas de $(6 \times 12 \times 120) \mathrm{cm}^{3}$, aqui consideradas como repetições do lote, que foram doadas por empresas, já nesse formato e dimensões. $\mathrm{Na}$ maioria das vezes (exceção se faz ao lote 1, no qual a madeira já estava previamente desdobrada em vigas), da madeira em toras disponibilizada nas empresas doadoras, sob acompanhamento da equipe de pesquisa, nas próprias empresas eram desdobradas as 12 vigas, contemplando-se a maior variação possível nas toras utilizadas, mas resguardando-se que elas (toras) pertencessem a uma mesma "partida".

De cada viga foi produzido um caibro com dimensões aproximadas de $(6 \times 6 \times 120)$ $\mathrm{cm}^{3}$, retirado da região da viga que apresentava maior homogeneidade do material e, por conveniência, menor incidência de defeitos.

Cada caibro era desdobrado ao meio em seu comprimento, resultando dois caibros com cerca de $50 \mathrm{~cm}$, que se constituíram, por fim, no material para os testes de calibração do equipamento. 
Tabela $N^{\circ} 1$

DADOS PRINCIPAIS DOS LOTES DE MADEIRA EMPREGADOS

\begin{tabular}{|c|c|c|c|}
\hline Lote & Madeira & Procedência & Características do lote \\
\hline 1 & $\begin{array}{l}\text { Goupia glabra } \\
\text { (Cupiúba) }\end{array}$ & $\begin{array}{l}\text { Murba Madeiras } \\
\text { Botucatu-SP }\end{array}$ & $\begin{array}{l}\text { Lote amostrando espécie nativa de uso corrente } \\
\text { na confecção de estruturas de madeira }\end{array}$ \\
\hline 2 & E.citriodora & \multirow{2}{*}{$\begin{array}{l}\text { Madeireira São } \\
\text { Caetano } \\
\text { Itatinga - SP }\end{array}$} & \multirow{2}{*}{$\begin{array}{l}\text { Lote amostrando madeira de espécie de } \\
\text { reflorestamento de uso potencial como dormente. } \\
\text { Madeira com idade superior a } 40 \text { anos }\end{array}$} \\
\hline 3 & E.citriodora & & \\
\hline 4 & E. saligna & \multirow{5}{*}{$\begin{array}{l}\text { PREMA } \\
\text { Madeira tratadas } \\
\text { Rio Claro - SP }\end{array}$} & \multirow{5}{*}{$\begin{array}{l}\text { Lotes amostrando madeiras de espécies de } \\
\text { reflorestamento com uso na produção de } \\
\text { dormentes. Madeira amostrada da serraria de } \\
\text { empresa fornecedora de dormentes para as } \\
\text { concessionárias das ferrovias brasileiras }\end{array}$} \\
\hline 5 & E. citriodora & & \\
\hline 6 & E. grandis & & \\
\hline 7 & E. tereticornis & & \\
\hline 8 & E. urophylla & & \\
\hline 9 & E. citriodora & \multirow{4}{*}{$\begin{array}{l}\text { Moretto } \\
\text { Madeira de } \\
\text { Eucalipto } \\
\text { Botucatu - SP }\end{array}$} & \multirow{2}{*}{$\begin{array}{l}\text { Lotes amostrando madeiras com lenho com } \\
\text { predominância de alburno }\end{array}$} \\
\hline 10 & E. citriodora & & \\
\hline 11 & E. citriodora & & \multirow{2}{*}{$\begin{array}{l}\text { Lotes amostrando madeiras com lenho com } \\
\text { predominância de alburno }\end{array}$} \\
\hline 12 & E. citriodora & & \\
\hline 13 & $\begin{array}{l}\text { Bagassa } \\
\text { guianenses } \\
\text { (Tatajuba) }\end{array}$ & $\begin{array}{l}\text { MOHR Madeiras } \\
\text { São Paulo - SP }\end{array}$ & $\begin{array}{l}\text { Lote amostrando espécie nativa de elevada } \\
\text { densidade, com uso potencial na produção de } \\
\text { dormentes }\end{array}$ \\
\hline 14 & E.grandis & $\begin{array}{l}\text { Duratex S/A } \\
\text { Botucatu - SP }\end{array}$ & $\begin{array}{l}\text { Lotes amostrando madeiras de reflorestamento } \\
\text { com grande predominância de alburno. Madeira } \\
\text { com idade de } 6 \text { anos. }\end{array}$ \\
\hline 15 & E.grandis & $\begin{array}{l}\text { Duratex S/A } \\
\text { Botucatu - SP }\end{array}$ & $\begin{array}{l}\text { Lotes amostrando madeiras de reflorestamento } \\
\text { com grande predominância de alburno. Madeira } \\
\text { com idade de } 6 \text { anos. }\end{array}$ \\
\hline 16 & E.grandis & $\begin{array}{l}\text { Duratex S/A } \\
\text { Botucatu - SP }\end{array}$ & $\begin{array}{l}\text { Lotes amostrando madeiras de reflorestamento } \\
\text { com grande predominância de alburno. Madeira } \\
\text { com idade de } 6 \text { anos. }\end{array}$ \\
\hline
\end{tabular}

Assim, para cada lote de madeira, foram produzidos corpos-de-prova para ensaios de calibração (com 12 repetições cada).

Em cada lote (Tabela $\mathrm{N}^{\circ} 1$ ), os 12 caibros de $50 \mathrm{~cm}$ de comprimento, na umidade de recebimento da madeira, tiveram suas dimensões nominais finais ajustadas para $(5 \times 5 \times 50) \mathrm{cm}^{3}$ e nele foram feitos os ensaios de calibração do equipamento.

A Figura $\mathrm{N}^{\circ} 4$ apresenta as regiões dos caibros onde foram realizados os ensaios mecânicos nos corpos-de-prova de $50 \times 5 \times 5 \mathrm{~cm}$. 


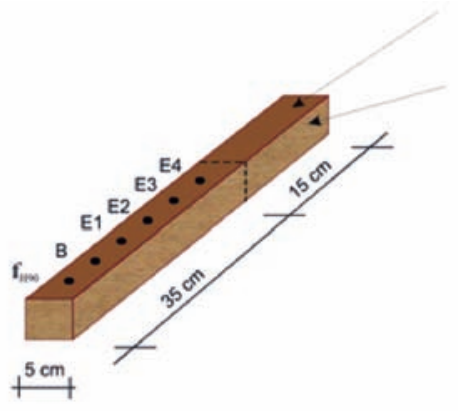

$$
\begin{array}{ll}
\mathrm{f}_{\mathrm{HgO}} & \text { - ensaio de dureza Janka normal às fibras } \\
\mathrm{HB} & \text { - ensaio de dureza Brinell }
\end{array}
$$

E1 a E4 - ensaios de dureza com durômetro portátil

Figura $N^{\circ} 4$

\section{REGIÕES DOS CAIBROS ONDE FORAM REALIZADOS OS ENSAIOS MECÂNICOS.}

\section{RESULTADOS E DISCUSSÃO}

Na Figura $\mathrm{N}^{\circ} 5$ estão registradas as correlações entre as durezas E1 a E3 (obtidas respectivamente nas situações 1 a 3 já descritas) e a dureza Janka, referência principal nos estudos aqui conduzidos. A regressão da dureza E4 com dureza Janka não teve a normalidade dos resíduos confirmada pelo teste estatístico de Shapiro.

Observa-se que todas as relações resultaram com coeficiente de determinação superior a 0,77 , que pode ser considerado bom. Coube novamente destaque à dureza E3, na medida em que a relação dela com a dureza Janka foi a melhor dentre as estudadas.
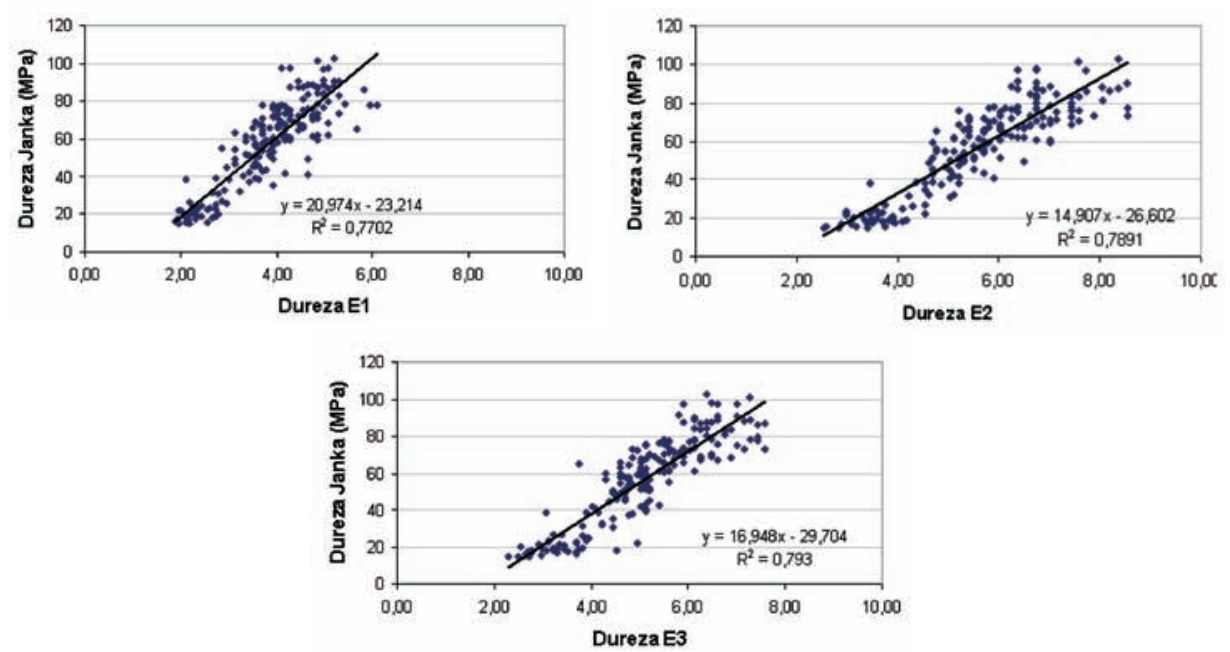

Figura $\mathrm{N}^{\circ} 5$

REGRESSÃO LINEAR ENTRE OS VALORES DA DUREZA E1, E2 E E3 E A DUREZA JANKA OBTIDA A PARTIR DOS RESULTADOS MENSURADOS NOS LOTES. 
Dessa forma, pelos resultados obtidos e considerando-se que as relações de regressão resultaram com coeficientes de determinação superiores a $70 \%$, assumidos normalmente como referencial mínimo para as pesquisas na área de Ciência e Tecnologia da Madeira pelo grupo do Laboratório de Ensaio de Materiais - FCA/UNESP pode-se concluir pela pertinência do uso do durômetro portátil para madeiras para inferir a dureza Janka.

A partir da equação de regressão da dureza E2 com dureza Janka (Figura 5), pode-se obter os valores de durezas E2 que corresponderiam às durezas Janka de $50 \mathrm{MPa}, 40 \mathrm{MPa}$ e $30 \mathrm{MPa}$, tidas como uma das exigências para classificação das madeiras para dormentes ( $1^{\mathrm{a}}$ classe, $2^{\mathrm{a}}$ classe e $3^{\mathrm{a}}$ classe). Assim, para a análise da dureza E2 correspondente a uma dureza Janka de $50 \mathrm{MPa}$, a equação de regressão forneceu o valor de E2 igual a 5,139 kgf/mm. Analogamente, para os valores de dureza Janka de $40 \mathrm{MPa}$ e $30 \mathrm{MPa}$, obtiveram-se valores de dureza E2 iguais a 4,468 kgf/mm e 3,797 kgf/mm, respectivamente.

Usando-se os valores assumidos de E2 como limites para as três situações, foram quantificados os corpos-de-prova que atendiam às metas estabelecidas, quais sejam, $\mathrm{fH} \geq 50$ $\mathrm{MPa}, 40 \mathrm{MPa} \leq \mathrm{fH}<50 \mathrm{M}$ e $30 \mathrm{MPa} \leq \mathrm{fH}<40 \mathrm{MPa}$

Análise semelhante foi conduzida para os valores da dureza E3 obtidos pela equação de regressão da Figura $\mathrm{N}^{\circ} 5$.

As Tabelas $\mathrm{N}^{\circ} 2$ e $\mathrm{N}^{\circ} 3$ resumem os resultados obtidos para as duas durezas (E2 e E3, respectivamente).

Tabela $N^{\circ} 2$

RESULTADOS DA CLASSIFICAÇÃO DOS CORPOS-DE-PROVA EM CLASSES, A PARTIR DE VALORES CARACTERÍSTICOS DA DUREZA JANKA, INFERIDOS PELA RELAÇÃO DE REGRESSÃO COM A DUREZA E2.

\begin{tabular}{|c|c|c|c|c|c|}
\hline 1 & 2 & 3 & 4 & 5 & 6 \\
\hline Classe & $\begin{array}{c}\text { Meta } \\
\text { para a } \\
\text { Dureza } \\
\text { Janka } \\
(\mathrm{MPa})\end{array}$ & $\begin{array}{c}\text { Dureza E2 } \\
\text { corresponde à } \\
\text { meta }(\mathrm{kgf} / \mathrm{mm}) \\
\text { Valores } \\
\text { estimados pela } \\
\text { regressão }\end{array}$ & $\begin{array}{c}\text { Quantidade de } \\
\text { c.p. } \\
\text { selecionados } \\
\text { pela dureza E2 } \\
\text { (a partir da } \\
\text { exigência da } \\
\text { coluna 3) }\end{array}$ & $\begin{array}{c}\text { Quantidade } \\
\text { de } \\
\text { c.p. que } \\
\text { atingiram a } \\
\text { meta } \\
\text { (expressa na } \\
\text { coluna 1) }\end{array}$ & $\begin{array}{c}\text { Acerto } \\
\text { (\%) } \\
\text { Obtido pela } \\
\text { relação de } \\
\text { valores das } \\
\text { colunas 5 e 4 }\end{array}$ \\
\hline 1 & $\mathrm{fH} \geq 50$ & E2 $\geq 5,139$ & 126 & 117 & 92,8 \\
\hline 2 & $40 \leq \mathrm{fH}<50$ & $4,468 \leq \mathrm{E} 2<5,139$ & 21 & 17 & 81,0 \\
\hline 3 & $30 \leq \mathrm{fH}<40$ & $3,797 \leq \mathrm{E} 2<4,468$ & 17 & 6 & 35,3 \\
\hline 4 & $\mathrm{fH}<30$ & $\mathrm{E} 2<3,797$ & 28 & 27 & 96,4 \\
\hline
\end{tabular}


Tabela $\mathrm{N}^{\circ} 3$

RESULTADOS DA CLASSIFICAÇÃO DOS CORPOS-DE-PROVA EM CLASSES, A PARTIR DE VALORES CARACTERÍSTICOS DA DUREZA JANKA, INFERIDOS PELA RELAÇÃO DE REGRESSÃO COM A DUREZA E3.

\begin{tabular}{|c|c|c|c|c|c|}
\hline 1 & 2 & 3 & 4 & 5 & 6 \\
\hline Classe & $\begin{array}{c}\text { Meta } \\
\text { para a } \\
\text { Dureza } \\
\text { Janka } \\
\text { (MPa) }\end{array}$ & $\begin{array}{c}\text { Dureza E3 } \\
\text { corresponde à } \\
\text { meta }(\mathrm{kgf} / \mathrm{mm}) \\
\text { Valores } \\
\text { estimados pela } \\
\text { regressão }\end{array}$ & $\begin{array}{l}\text { Quantidade de } \\
\text { c.p. } \\
\text { selecionados } \\
\text { pela dureza E3 } \\
\text { (a partir da } \\
\text { exigência da } \\
\text { coluna 3) }\end{array}$ & $\begin{array}{l}\text { Quantidade } \\
\text { de } \\
\text { c.p. que } \\
\text { atingiram a } \\
\text { meta } \\
\text { (expressa na } \\
\text { coluna 1) }\end{array}$ & $\begin{array}{c}\text { Acerto } \\
(\%) \\
\text { Obtido pela } \\
\text { relação de } \\
\text { valores das } \\
\text { colunas } 5 \\
\text { e } 4\end{array}$ \\
\hline 1 & $f_{H} \geq 50$ & $E 3 \geq 4,703$ & 125 & 116 & 92,8 \\
\hline 2 & $40 \leq f_{H}<50$ & $4,113 \leq E 3<4,703$ & 25 & 19 & 76,0 \\
\hline 3 & $30 \leq \mathrm{f}_{\mathrm{H}}<40$ & $3,523 \leq \mathrm{E} 3<4,113$ & 15 & 5 & 33,0 \\
\hline 4 & $f_{H}<30$ & $E 3<3,523$ & 27 & 26 & 96,3 \\
\hline
\end{tabular}

Nota-se que, nos dois casos, as durezas E2 e E3, avaliadas com o durômetro portátil para madeiras, tiveram um acerto de $92,8 \%$, quando o objetivo era selecionar madeiras com dureza Janka igual ou superior a $50 \mathrm{MPa}$. Igual análise, para a seleção de durezas Janka entre $40 \mathrm{MPa}$ e $50 \mathrm{MPa}$ (aqui denominada classe 2), leva a um acerto de 81,0\% quando a mensuração é de dureza E2 e 76,0\%, quando a mensuração é de dureza E3.

Para as duas últimas classes (classes 3 e 4), os percentuais de acerto foram bastante variáveis, tanto nos casos de E2 quanto de E3. Assim, para a classe 3, o percentual de acerto ficou em aproximadamente 35\% quando da avaliação das durezas E2 e E3, e 96\% para a classe 4.

Entende-se, contudo, que a maior justificativa de uso do equipamento se daria em condições de seleção de madeiras de categorias superiores, com o objetivo claro de separálas das categorias inferiores.

Nessas situações o equipamento se comportou com um percentual de acerto elevado, que o habilita para esse emprego.

\section{CONCLUSÕES}

A partir da interpretação dos dados obtidos no programa experimental aqui desenvolvido, as conclusões principais do trabalho são:

Das várias energias estudadas para endentação com uso do durômetro portátil, a que revelou maior proximidade de resultados de dureza com aqueles obtidos pelo método de referência deste trabalho - dureza Janka - foi a energia de $200 \mathrm{kgf.mm}$. 
Os coeficientes de determinação $\left(R^{2}\right)$ das regressões entre a dureza E2 e a dureza Janka e entre a dureza E3 e Janka foram de 0,79. Esses coeficientes elevados revelam a possibilidade de inferência da dureza Janka a partir dessas duas durezas, mensuradas com o durômetro portátil para madeiras.

O equipamento teve bom comportamento no processo de classificação de madeiras, quando se utiliza a dureza Janka como parâmetro definidor das classes. Para as classes de dureza superiores $\left(\mathrm{f}_{\mathrm{H}} \geq 50 \mathrm{MPa}\right.$ e $\left.40 \mathrm{MPa} \leq \mathrm{f}_{\mathrm{H}}<50 \mathrm{MPa}\right)$ a classificação a partir da dureza E2 revelou percentual de acerto de $92,8 \%$ e $81,0 \%$, respectivamente. Quando a classificação foi feita a partir da mensuração de E3, os percentuais de acerto foram $92,8 \%$ e $76,0 \%$.

\section{REFERÊNCIAS BIBLIOGRÁFICAS}

Associação Brasileira de Normas Técnicas, 1982. NBR 7511 Dormentes de madeira. Rio de Janeiro: ABNT.

Ballarin, A.W., 1996. Dormentes de madeira: a necessidade de uma revisão normativa. (1996) In: Congresso Internacional de Material Rodante, Via Permanente e seus Acessórios, 1996. Anais. CB-06/ABNT.

Ballarin, A.W.; Franco, N.; Yojo, T., 1998. Calificación de maderas brasilenãs nativas y de reforestacionas para durmientes. In: Congreso Latinoamericano IUFRO, 1998, Valdívia-Chile. Actas (CD-ROM). Valdívia: IUFRO.

Ballarin, A.W., 1999 Desempenho mecânico de dormentes prismáticos de Eucalyptus citriodora. Botucatu, FCA/UNESP, 204 p.Tese (Livre - docência em Propriedades mecânicas e estruturas de madeira), Faculdade de Ciências Agronômicas, UNESP.

Bektas, I., Alma, M.H., 2001. Determination of the relationships between Brinell and Janka hardness of eastern beech (Fagus orientalis LIPSKY). Forest Products Journal, v. 51, $n^{\circ}$. 11/12 p.84-87.

Colenci, A.R., 2002. Qualificação mecânica de madeiras para uso como dormente ferroviário. Botucatu, UNESP, 90 p. Dissertação (Mestrado em Agronomia - Energia na Agricultura) Faculdade de Ciências Agronômicas, Universidade Estadual Paulista.

Colenci, A.R., 2006. Desenvolvimento de equipamento para avaliação em campo da dureza de madeiras para dormente ferroviário, 90 p. Tese (Doutorado em Agronomia - Energia na Agricultura) - Faculdade de Ciências Agronômicas, Universidade Estadual Paulista.

Colenci, A. R. e Ballarin, A.W. e Rocha, R.R., 2002. Ensaio de dureza na classificação mecânica de dormentes de madeira. In: VIII EBRAMEM - Encontro Brasileiro em Madeiras e Estruturas de Madeira, Uberlândia - MG. Anais do VII EBRAMEM. 
Dal Pogetto, M.H.F.A., 2005. Ensaios de Dureza Paralela e Normal às Fibras da Madeira, Relatório Científico - UNESP -Faculdade de Ciências Agronômicas, Universidade Estadual Paulista Botucatu.

Niederauer, F.R., 1982. Emprego da madeira de eucalipto como dormente. In: Encontro Brasileiro em Preservação de Madeiras, 1. Anais... IBDF/IPT/ABPM, p.203 - 32.

Nogueira, M.C.J.A.; Lahr, F.A.R., 1992. Indicações para o emprego de dezesseis espécies de eucaliptos na construção civil. In: Encontro Brasileiro de Madeiras e de Estruturas de Madeira, São Carlos. Anais.São Carlos: LaMEM - EESC - USP, v.1., p. 37 - 48.

Sales, A.; Lahr, F.A.R., 1992. Características de resistência mecânica de espécies de eucalipto do Estado de São Paulo. In: Encontro Brasileiro Em MADEIRAS e Estruturas de Madeira, 4, São Carlos. Anais...São Carlos: LAMEM, EESC, USP, v.3, p 91-101.

Tuset, R. e Taibo, R.G., 1987. Producción de durmientes de eucalipto. Montevideo: Faculdad de Agronomia, 1987. 36 p . (Boletín de Investigación, 4). 
